\title{
LA LIBERTAD DE EXPRESIÓN ARTÍSTICA UNA PRIMERA APROXIMACIÓN
}

\author{
Víctor J. Vázquez Alonso
}

\begin{abstract}
SUMARIO: 1. INTRODUCCIÓN: LA LIBERTAD ARTÍSTICA COMO PROBLEMA CONSTITUCIONAL. 2. EL ARTE COMO COMUNICACIÓN. 3. LA DIMENSIÓN OBJETIVA DE LA LIBERTAD ARTÍSTICA. EL ARTISTA EN EL ESTADO CONSTITUCIONAL. 4. EL ARTISTA Y EL DERECHO A LA IRREVERENCIA.
\end{abstract}

\section{INTRODUCCIÓN: LA LIBERTAD ARTÍSTICA COMO PROBLEMA CONSTITUCIONAL}

En ciertos ámbitos el derecho constitucional lo tiene difícil para ser una disciplina modesta. Abordar determinadas cuestiones constitucionales para las cuales el derecho no ha desarrollado una autonomía conceptual, a través de un mero lenguaje autorreferencial, o de una suerte de talmudismo jurisprudencial, no sólo supone incurrir en el viejo vicio que los humanistas imputaban a los jurisconsultos, de citarse a sí mismos como si su trabajo fuera el más arduo e interesante, sino que, inequívocamente, lleva implícito una suerte de soberbia disciplinar. Más modesto parece, en principio, aproximarse a estas materias constitucionales, dando por supuestas, no sólo las necesarias relaciones de vecindad con otras disciplinas afines, sino también, en ocasiones, con estudios directamente ajenos a lo jurídico. El problema, en estos supuestos, radica en que no es sencillo evitar adentrarse en debates sobre los cuales el constitucionalista está lejos de ser el más versado. La forma de equivocarse no es otra, en esta ocasión, que la de meterse en camisas de once varas. Es por esto que la solución más sensata en estos casos termina siendo la de marginar la cuestión, no porque su importancia sea menor, sino porque es muy difícil profundizar en ella sin pisar en falso. Pues bien, una de esas cuestiones tradicionalmente marginadas en los estudios de derecho constitucional es la libertad artística. Es difícil encontrar, en este sentido, referencias bibliográficas específicas a este derecho $\mathrm{y}$, al mismo tiempo, 
como veremos, es llamativa la forma en la que cual los jueces rehúsan entrar a definir constitucionalmente el ámbito protegido por esta libertad, que pasa por ser para los juristas, una suerte de hija bastarda y discreta de la libertad de expresión. El derecho a la libertad artística, o si se prefiere, la libertad de expresión artística ${ }^{1}$, ha sido a la postre un derecho que padece una carencia de autonomía conceptual con respecto a otras libertades de comunicación como son la libertad de expresión o la libertad de información, y que en gran medida a causa de ello, adolece de un protección jurídica de perfil bajo.

Obviamente, las razones de ello radican, en gran medida, en las propias dificultades que existen para definir en abstracto el contenido de este derecho. Dificultades que son inherentes, sin duda, al propio carácter escurridizo de la definición de arte, algo sobre lo que alguno podría decir que no se ha avanzado demasiando desde los intentos ilustrados hasta nuestros días ${ }^{2}$. Así, en ciertos casos, determinar cuándo nos encontramos ante una actividad artística o cuándo nos encontramos ante una obra de arte, son cuestiones que, especialmente desde las vanguardias, no resultan ni mucho menos pacíficas en los propios campos de la filosofía y de la estética ${ }^{3}$, lugares donde, en principio, el jurista podría acudir en busca de ayuda.

En cualquier caso, la intuición nos dice que puede establecerse una diferenciación entre la libertad de expresión, en tanto libre transmisión de ideas, opiniones y juicios de valor, de determinadas formas de expresión que, independientemente de que tras ellas subyazcan ideas u opiniones, están dirigidas a provocar una concreta emoción estética. La libertad artística podría ser vista, desde esta perspectiva, como una suerte de modalidad específica de la libertad de expresión que, aun siendo diferenciada de esta, en tanto a su concreta intencionalidad estética, es susceptible de ser objeto de una aproximación jurídica similar en su tratamiento, dado que en ambos casos subyace un valor jurídico común que sería la libertad de comunicación. Desde esta perspectiva, más que un marco conceptual propio, podría plantearse sin más la plena aplicación de la doctrina constitucional de la libertad de expresión a los supuestos donde esa expresión pueda calificarse de artística.

Sin embargo, la propia idea de que el arte es una actividad siempre comunicativa o discursiva no es siempre aceptada, y con ello, tampoco se admite que la doctrina judicial de la libertad de expresión haya de proteger en todo caso la obra de arte. Por ejemplo, el profesor Tushnet ha manifestado sus dudas acerca de si realmente puede considerarse que la obra del pintor expresionista abstracto Jackson Pollock transmite algún tipo de mensaje o discurso

${ }^{1}$ Aunque como veremos, hablar de expresión artística, en buena medida implica ya un enfoque determinado que repercute en el propio tratamiento jurídico de este derecho.

${ }^{2}$ Vid. Adler, A. M., «The Folly of Defining Art», en The New GateKepers: Emerging Challenges to Free Expression in the Arts, 2004.

3 Vid. Freeland, C., But is it Art?, Oxford, 2001. 
que haya de estar amparado por la Primera Enmienda. En cierta medida, estas posturas se sustentan sobre la tesis filosófica de que el arte no es siempre cognoscitivo o comunicativo, sobre todo desde la irrupción de ciertas manifestaciones artísticas, propias de la modernidad y la post-modernidad, marcadas por el hermetismo o el subjetivismo radical.

En segundo lugar -y aquí nos movemos en un ámbito sin duda más cómodo para los constitucionalistas- buena parte de las voces críticas que rechazan la extensión de la doctrina judicial de la libertad de expresión a la libertad artística, lo hacen sobre el presupuesto de que en ningún caso puede considerarse que la dimensión institucional u objetiva de la libertad artística es asimilable a la de la libertad de expresión. Dicho de otra forma, para algunos autores, la posición jurídica privilegiada de la libertad de expresión se fundamenta en su contribución específica a la formación de una opinión pública libre, la cual adquiere su máximo exponente en aquellos supuestos que puedan ser subsumibles dentro del concepto de discurso político. Para estos autores, lo artístico ha de considerarse como un territorio autónomo de lo político, y, en cualquier caso, la contribución de la libertad de expresión artística a la opinión pública, no podría ser equiparable a la de la libertad de expresión. Una tesis que, como fácilmente puede deducirse, conduce a afirmar que las restricciones de esta libertad no han de someterse al estricto escrutinio judicial propio de las libertades de información y de expresión. Tesis que, como se verá más adelante, parece estar implícita en buena parte de las sentencias del Tribunal Europeo de Derechos Humanos.

Como se ha dicho, la tarea de definir la libertad artística como derecho suele provocar la evasión del jurista, y, por supuesto, en estas páginas no se va a romper con esa prudente tradición. Serán además muchos los cabos sueltos y las cuestiones sobre las que no hay nada que decir, y muchas también las ideas sobre las que me reservo el derecho de cambiar de opinión. No obstante, si se va a intentar en este trabajo poner en cuestión algunos presupuestos en base a los cuales, los tribunales y parte de la doctrina rehúsan otorgar a la libertad artística la misma protección jurídica que al discurso político o a la libertad de información. En concreto, se intentará defender que, incluso en su versión más hermética y autorreferencial, propia de las vanguardias o de la postmodernidad, la obra de arte ha de ser considerada por el derecho como un fenómeno intrínsecamente comunicativo que no puede, por lo tanto, quedar al margen de la protección de la libertad de expresión. En segundo lugar, frente a las tesis que, aun extendiendo la protección de la libertad de expresión a la libertad artística, niegan que cualquier restricción a esta última haya de someterse a estricto escrutinio, al no ser subsumible la obra de arte dentro del concepto de political speech, intentaremos poner de manifiesto cómo la inequívoca dimensión institucional u objetiva de la libertad artística dentro del estado constitucional o, si se prefiere, dentro de la cultura del estado cons- 
titucional, justifica un tratamiento judicial análogo al del discurso político o la libertad de información.

Finalmente, en la última parte de este artículo llamaremos la atención sobre algunas notas que caracterizan la libertad de expresión artística en relación a las libertades de expresión e información, especificidades que, en nuestra opinión, justifican una la autonomía conceptual de esta libertad.

\section{EL ARTE COMO COMUNICACIÓN}

En un conocido ensayo, el profesor de Oxford, Quentin Skiner, defiende que, al contrario de lo que gran parte de los comentaristas habían sostenido hasta entonces, tras los frescos que Ambrogio Lorenzetti pintara para la Sala dei Nove del Palazzo Comunale de Siena no se esconde un una síntesis de la filosofía aristotélico-tomista, sino una teoría republicana del buen gobierno, inspirada en los clásicos de la Antigua Roma, que pondría de manifiesto la consolidación en la época prerrenacentista de una filosofía política que se sustentaba sobre una serie de conceptos propios del pensamiento romano clásico, como la virtud, la concordia o la igualdad (aequitas) ${ }^{4}$. Obviamente, es difícil negar, sobre todo después de leer a Skinner, que esta obra artística, más allá de su excelencia técnica o estética, no constituya en sí misma una fuente de conocimiento y de reflexión política, y no sólo desde el punto de vista histórico, sino desde el punto de vista exclusivamente conceptual. Detrás de la obra de Lorencetti, encontramos inequívocamente un discurso. Ahora bien, también es cierto que de los frescos de Lorenzetti a la obra Jackson Pollock que tanto preocupa a Tushnet ${ }^{5}$, o a la de Marcel Duchamp con sus váteres convertidos en fuentes, hay un espacio de tiempo en el que el arte, o por lo menos ciertas manifestaciones de lo artístico, han perdido su carácter objetual, su conexión con la tradición narrativa y figurativa, su carácter cultual, y su propia pretensión de verdad ${ }^{6} \mathrm{e}$

\footnotetext{
${ }^{4}$ SKINNER, Q., El artista y la filosofia politica. El Buen Gobierno de Ambrogio Lorencetti, Ed. Trotta, Madrid, 2009.

5 Tushnet, M., «Art and the First Amendment», Columbia Journal of Law and the Arts, Vol. 35, 2012. La insistencia en Pollock no es casual, y es que en la conocida sentencia Hurley v. Irish American Gay, Lesbian, and Bisexual Group of Boston, sobre la prohibición de la participación de Gays y Lesbianas en la anual marcha de los irlandeses por Boston, el Juez Souter, defendió una visión digamos extrínseca de la libertad de expresión, tomando como referencia el receptor del mensaje, para lo cual no dudo en afirmar que los cuadros de Jackson Pollock están amparados por la Primera Enmienda. Asunto Hurley vs. Irish American Gay, Lesbian, and Bisexual Group of Boston, Sentencia del TS de EEUU de 1995 (515 U.S. 557)

${ }^{6}$ Sobre este abandono del artista de cualquier indagación científica a través de su obra, insiste Max Weber. En la frontera de la modernidad «los artistas experimentales del tipo Leonardo y de los innovadores musicales, la ciencia significaba el camino hacia el arte verdadero, que para ellos era también el de la verdadera naturaleza. Había que elevar
} 
incluso de inteligibilidad ${ }^{7}$. En definitiva, usando la expresión de Gadamer, hay un momento en el que el arte no quiere ser otra cosa que arte ${ }^{8}$.

Todo esto podría llevarnos a la conclusión de que, en tanto pertenecientes a un mundo hermético y confuso, aquellas manifestaciones artísticas no comprometidas con la inteligibilidad -ni mucho menos esporádicas en nuestros postmodernos tiempos- no pueden ser analizadas en ningún caso desde la óptica de la libertad de expresión sin adulterar los contornos de este derecho. Tushnet, por lo tanto, estaría en lo cierto, y aplicar a un cuadro de Pollock la protección de la Primera Enmienda sería algo así como darle a un perro una flauta para que toque. Sin embargo, creo que la tesis de Tushnet no es fácil de asumir si partimos de un concepto extensivo acerca de qué tipo de actividades humanas son las que contribuyen a la definición de nuestra cultura política e, igualmente, si atendemos a la propia complejidad de la relación que los movimientos artísticos autorreferenciales y, en principio, ajenos a cualquier otro objeto que no sea el arte en sí han tenido con el poder político. Vayamos a ello.

La irrupción de la modernidad artística, que suele situarse en la obra de Baudelaire ${ }^{9}$, no sólo daría lugar a un culto de lo nuevo, sino también a una suerte heterodoxia moral del artista. Ciertamente, desde entonces, la conciencia del artista se va a forjar, en muchas ocasiones, en un concreto pathos marginal ${ }^{10}$, fascinado por la irreverencia, la negación de la tradición e, incluso, por el compromiso con la absoluta inutilidad de su obra. La modernidad bien puede resumirse, en este sentido, a través del aforismo de Jean-Luc Godard, «la cultura es la regla, el arte es la excepción ${ }^{11}$. Desde luego, esta ruptura cultural, no sólo va a ser formal, y tampoco van a faltar ejemplos en los que el artista va avalar su obra manifestando su absoluto rechazo a cualquier canon clásico de moralidad. Sin embargo, el hecho de que el arte se constituya en un espacio de reflexión autónoma no significa que no entre en

el arte a la categoría de ciencia, y esto significaba sobre todo que, por su rango social y el sentido de su vida, el artista tenía que ser equiparado con el doctor. Esta sería la ambición que late en el fondo del Tratado de la Pintura de Leonardo... Esto sonaría como una blasfemia en los oídos de la juventud. WeBer, M., El político y el cientifico, Ed. Alianza, Madrid, 2007, p. 206.

${ }^{7}$ Como señalara Ortega con la modernidad «no se trata de que a la mayoría del público no le guste la obra joven y a la minoría sí. Lo que sucede es que la mayoría, la masa no la entiende» Vid. ORTEGA Y GASSET, J., «La deshumanización del arte», en ORTEGA Y Gasset, J., Obras Selectas, Ed. Espasa Libros, Madrid, p. 408.

8 Vid. Gadamer, H.-G., La actualidad de lo bello, Barcelona, 2010, p. 59.

9 Vid. Habermas, J., «La Modernidad: un proyecto inacabado», en El debate Modernidad-Postmodernidad, Ed. Punto Sur, Buenos Aires, 1987, p. 131.

${ }^{10}$ Benjamin, W., «Charles Baudelaire. Un lírico en la época del altocapitalismo», en Obras, libro I/vol. 2, Madrid, pp. 92 y ss.

11 Vid. Godard, J.-L., Historie(s) du cinema, Gallimard, Paris, 1998. 
contacto ni incida, a través de unas pautas propias, en la formación de la opinión pública y, con ello, en la definición de una determinada comunidad política. Así, incluso si consideramos el carácter autorreferencial y hermético de ciertas expresiones artísticas propias de la vanguardia, lo cierto es que éstas nunca han dejado de constituirse, aún desde su voluntaria marginalidad, en una suerte de espejo cóncavo de una sociedad política en un tiempo determinado, de tal forma que es difícil comprender ese tiempo -el que acoge la propia modernidad - sin acercarse a ellas. Al mismo tiempo, y aunque sea paradójico, es precisamente en el apogeo de la subjetivación y el hermetismo artístico, cuando, al mismo tiempo, como avanzara Malraux a través de su idea de museo imaginario ${ }^{12}$, la obra de arte adquiere su máxima publicidad, desprendida de cualquier otra utilidad que no sea la de su exhibición, y se multiplican asimismo las posibilidades de su reproducibilidad técnica ${ }^{13}$. En definitiva, el arte no referencial ni objetual no es, sin embargo, un arte introvertido, sino que es, podríamos decir, un arte radicalmente destinado a ser objeto de comunicación. Dicho de otra forma, aunque no sea siempre discurso (speech) el arte no va a dejar de ser expresión.

En cualquier caso, hay algo que, desde la perspectiva del derecho y, en concreto, del derecho constitucional, no puede ser pasado por alto, y es el hecho de que, incluso estas corrientes artísticas autorreferenciales y herméticas han constituido, en la práctica, y desde sus planteamientos exclusivamente estéticos, un quebradero de cabeza para distintos modelos políticos de sociedad antitéticos entre sí. Un ejemplo inmejorable de ello sería el de la difícil convivencia de las vanguardias artísticas con el socialismo, cuya proyecto de politización del arte se encontró desde el principio con la resistencia e movimientos también radicalmente antiburgueses, como el surrealismo $^{14}$ o el dadaísmo, pero que, desde sus presupuestos estéticos, consti-

12 Vid. MalrauX, A., Les voix du silence. Le musée imaginaire, Paris, 1951.

13 Vid. Benjamín, W., «La obra del arte en la época de su reproductibilidad técnica», en Obras, libro I/vol. 2, Madrid, pp. 12-47

14 Valga como ejemplo la postura que defendieron Breton, Trosky y Diego Rivera en su célebre Manifiesto por un arte revolucionario independiente: «En cuestiones de creación artística, importa esencialmente que la imaginación escape a toda clase de imposiciones, que bajo ningún pretexto se deje imponer moldes. A quienes pretendan presionarnos, tanto hoy como mañana, para que consintamos que el arte se vea sometido a una disciplina que consideramos radicalmente incompatible con sus medios, oponemos un rechazo inapelable y nuestra voluntad deliberada de atenernos a la fórmula «toda clase de licencias para el arte». La imposibilidad de adecuar este compromiso libérrimo, en el molde del realismo socialista puede verse bien a la luz este párrafo cuyo autor es otro de los fundadores junto a Breton del Surrealismo, el poeta Louis Aragon, quien luego abrazo la ortodoxia del realismo socialista: «Basta con que falte uno solo de los elementos exigidos al escritor por el realismo socialista para que la obra pierda el carácter realista socialista, para que quede reducida al naturalismo, al populismo, a la vulgarización sociólogica, para 
tuían un desafío frontal al realismo socialista a cuyo servicio debería someterse el arte, según terminaría interpretando la tradición marxista ${ }^{15}$. En este sentido, creo que es esclarecedor de hasta qué punto el arte no necesita un discurso o una explícita vocación política para convertirse en una cuestión política, el ensañamiento con el que la Rusia soviética practicó la censura musical, utilizando como parámetro de control el propio concepto de realismo socialista, frente a aquellos compositores calificados de formalistas como Malher, Stravisnky o Schönberg... cuya música fue proscrita durante décadas en la URSS. Otro tanto podríamos decir de la Alemania nazi donde, como es conocido, en 1937, y bajo la dirección personal Goebbels, se organizó una exposición que mostraba el paradigma de la «música degenerada» a través de las grabaciones, entre otros, de Mendelssohn, Mahler o Schönberg $^{16}$. Dos años antes, la exposición había versado sobre los paladines pictóricos de la degenerada modernidad, exhibiéndose entre otras tan aparentemente pacíficas y despolitizadas, en tanto herméticas, como las de Kandinsky o Paul Klee.

Pero sería un error pensar que las manifestaciones más autorreferenciales y herméticas de la libertad artística, propias de la modernidad, sólo han resultado incómodas para los regímenes totalitarios. Basta leer el trabajo clásico de Daniel Bell, sobre las debilidades de la sociedades capitalistas, para comprobar que para buena parte del pensamiento liberal-conservador, las vanguardias artísticas, con su carga desproporcionada de nihilismo, hedonismo e irracionalidad, habrían contribuido a socavar la ética protestante, basada en la responsabilidad, la racionalidad y el trabajo, y sobre la cual descansaría la prosperidad de las sociedades capitalistas ${ }^{17}$. En definitiva, por muy críptica que pueda ser una obra de arte de Pollock, parece que

arruinar, en definitiva, su carácter de obra de arte». Existe una antología contrastada de los textos estéticos de Bretón, A. y Aragón, L., Surrealismo frente a realismo socialista, Ed. Tusquets, Barcelona, 1978.

15 Puede verse un relato de relación entre vanguardia artística y pensamiento revolucionario, examinando las sinergias iniciales, y su progresivo distanciamiento hasta su enfrentamiento final, tras la Segunda Internacional, en HoBSBAwn, E., «El Socialismo y la Vanguardia», en Gente poco corriente. Resistencia, rebelión y jazz, Ed. Critica, Barcelona, 2013, pp. 148-159.

${ }_{16}$ Puede verse, en extenso, el conocido libro de Alex Ross, El ruido eterno, en especial el capítulo II, en el que comprende los años entre 1933 y 1945, y analiza paralelamente las políticas culturales en la Rusia de Stalin, la América de Roosevelt y la Alemania de Hitler. La censura musical durante el siglo XX, fue el tema de discurso del músico Carlos Prieto al recibir el Premio de la Escuela de Música de la Universidad de Yale, el texto está disponible en <http://www.letraslibres.com/revista/convivio/las-musicas-prohibidas-del-siglo-xx?page=full $>$, última consulta: 11.11.2014.

17 Vid. Bell, D., Las contradicciones culturales del capitalismo. Alianza Editorial. 2006, pp. 50 y ss. 
la misma, cuanto menos, transmite una decisión conceptual acerca de lo que es el arte que es susceptible de molestar a alguien que tenga una visión política de la sociedad como Daniel Bell, y que también, hubiera tenido muchas papeletas para ser exhibida en la exposición de arte degenerado en la Alemania del 1935, o para no pasar satisfactoriamente el test del realismo socialista en la Unión Soviética.

Es por todo esto que en un modelo político propio de una sociedad abierta, que reconduce parte de su legitimidad a los procesos informales de comunicación que se dan en la sociedad, resulta difícil no extender los presupuestos normativos de la comunicación, $\mathrm{y}$, en este caso, la protección jurídica propia de la libertad de expresión, a aquellas formas artísticas no figurativas, no narrativas ni objetuales, pero que, en cualquier caso, también participan, ya sea inconscientemente, en el proceso de reflexión que hace sobre sí misma una sociedad en un tiempo determinado. Como ha señalado el profesor Munkittrich, en su defensa de la música como una manifestación de la Primera Enmienda, aparte de apuntalar la propia individualidad, la expresión musical también puede promover la comunidad, introduce solidaridades y hay ejemplos más que evidentes de que puede erigirse en el elemento conductor y a su vez comunicativo de una cultura ${ }^{18}$. Para el estado constitucional, para una sociedad abierta, en definitiva, creo que no cabe otra comprensión del arte que la de un fenómeno comunicativo, a través del cual se participa de la propia cultura y que requiere por lo tanto de una protección jurídica que garantice esta libertad.

\section{LA DIMENSIÓN OBJETIVA DE LA LIBERTAD ARTÍSTICA. EL ARTISTA EN EL ESTADO CONSTITUCIONAL}

Asumiendo que la obra de arte siempre presenta un elemento comunicativo o cognoscitivo, la cuestión sigue siendo la de si al no tratarse en puridad de una manifestación genuina de political speech, debe o no la libertad del artista de beneficiarse de la posición procesal privilegiada que los tribunales normalmente otorgan a las libertades de expresión y de información cuando éstas entran en conflicto con otros bienes jurídicos. Como es conocido, ha sido la jurisdicción de la Corte Suprema norteamericana la que más ha contribuido a que en el constitucionalismo occidental se asuma esta lectura democrática de las libertades de expresión e información, de la que se deduce que cualquier limitación a los mismos ha de ser sometida a un estricto escrutinio judicial. A este respecto, es también en la propia literatura norteamericana de la Primera Enmienda donde podemos encontrar esta reticencia a la hora de extender a la expresión artística las garantías judicia-

18 Vid. MunktrRick, D., «Music as Speech. A First Amendment Category unto itself», Federal Communication Law Journal, Vol. 62, 2010, pp. 682-684. 
les propias del freedom of speech. Así, un autor como Robert Bork ha sostenido que solo pueden extenderse las garantías propias de la Primera Enmienda a aquellos discursos que se dirigen a nosotros como ciudadanos, es decir, que versan sobre la concreta cuestión de cómo somos gobernados, sin que, por lo tanto, la expresión artística, como tampoco la puramente académica, deban estar amparadas por el derecho a la libertad de expresión de la Primera Enmienda ${ }^{19}$. En una misma línea, como hemos visto, Tushnet considera que la protección de la Primera Enmienda se proyectaría sobre el discurso, no sobre cualquier comunicación, y en cualquier caso, solo alcanzaría su máxima intensidad cuando este discurso verse sobre la forma en la que somos gobernados ${ }^{20}$. A este respecto, incluso en un autor como Meiklejohn, quien, como es conocido, defendió una comprensión absoluta de la Primera Enmienda que incluía también bajo su protección a la literatura y las artes, podemos encontrar una cierta reticencia a juzgar bajo un estricto escrutinio los límites a aquellas manifestaciones artísticas cuya dimensión, digamos política, no sea de alguna forma evidente. Y es que, para Meiklejohn, la protección ha de extenderse a toda forma de comunicación que pueda nutrir de conocimiento y sensibilidad crítica a los ciudadanos en relación al gobierno de la sociedad en la que viven, de tal forma que en aquellos supuestos donde pueda deducirse que lo que una determinada obra de arte transmite es completamente ajena a esta cuestión, se puede deducir que su protección constitucional bajo la Primera Enmienda deberá de ser de una intensidad menor ${ }^{21}$. En cierta medida, como señala algún autor, la libertad artística parece situarse en una suerte lugar intermedio en el grado de protección que le concede la Primera Enmienda de la Constitución americana, aproximándose a nivel máximo de protección sólo en aquellos supuestos en los que la obra de arte sirve de vehículo a un discurso político ${ }^{22}$. Supuestos en los que, en realidad, no se protegería la expresión artística en sí, sino este discurso al que da cuerpo y forma.

Esta ha sido, creo, la lógica a la que ha respondido buena parte de la escasa jurisprudencia en la que el Tribunal Europeo de Derechos Humanos ha juzgado si ciertas medidas limitativas de la libertad artística contravenían el artículo 10 del Convenio. Si no me equivoco, la primera sentencia en la que el Tribunal entra a valorar si se ha producido una vulneración de la libertad

19 Bork, R., «Neutral Principles and Some First Amendment Problems», Indiana Law Journal, Vol. 47, 1971, pp. 27.

${ }^{20}$ Tushnet, M., «Art and the First Amendment», Columbia Journal of Law and the Arts, Vol. 35, 2012, pp. 208-216.

${ }_{21}$ Vid. Meiklejohn, A., "The First Amendment is an Absolute», Supreme Court Review, 1961, pp. 246-256,

22 Vid. NAHMOD, S. H., «Artistic Expression and Aesthetic Theory: The Beautiful, the Sublime and the First Amendment», Wisconsin Law Review, 1987, pp. 236-237. 
artística tiene su origen en la condena por blasfemia en Reino Unido a la Gay News por la publicación del poema de Jemes Kirkuk, The Love That Dares to Speak its Name, una composición en la cual se recrean escenas de sexo entre Jesús, sus discípulos y otros protagonistas de pasajes evangélicos como los centuriones romanos que custodiaron a Jesús de Nazaret o el propio Poncio Pilato. La Comisión no encontró en esta condena una injerencia en el artículo 10 del Convenio, dado que la protección de los sentimientos religiosos constituía un fundamento legítimo para la imposición de ciertos límites por parte de los Estados. Casi diez años más tarde, en Müller v. Suiza, la mayoría del Tribunal entendió que la condena por obscenidad impuesta a un artista que había exhibido una obra cargada de lascivia en un exposición de arte contemporáneo, no vulneraba el artículo 10 del Convenio, dado que los estados miembros disfrutan de un amplio margen de apreciación nacional a la hora de circunscribir cuál ha de ser la protección de moral pública en una sociedad determinada. Un parámetro de análisis que se va a mantener en dos conocidas sentencias en las que, en este caso, el material comprometido era de carácter audiovisual. En la primera de ellas, Otto Preminguer Institute v. Austria $^{23}$, se entendió que las autoridades austriacas no habían vulnerado el artículo 10 del Convenio al impedir la exhibición en una sala de un cine de arte y ensayo de una película que satirizaba el cristianismo recreando, entre otras cosas, al Dios de los cristianos como un anciano senil y a Jesucristo como un deficiente mental. Para el Tribunal, el especial margen de apreciación que ha de conferirse a las autoridades nacionales en cuestiones relacionadas con la religión, donde las diferencias históricas y sociológicas entre los países miembros son evidentes, legitimaba a los jueces austríacos para prohibir la exhibición de una película que podía herir los sentimientos religiosos de una mayoría de la sociedad. En Wingrove v. Reino Unido ${ }^{24}$, la obra que había sido censurada, no concediéndosele licencia de exhibición, era una película sobre el éxtasis de Santa Teresa de Ávila, en la cual podía verse cómo la monja carmelita tenía experiencias eróticas con Jesucristo. Para el juez de Estrasburgo, su prohibición tampoco había supuesto una vulneración del Convenio, considerando nuevamente este especial margen de apreciación del que disfrutan los estados en este ámbito.

Todas las sentencias que acabamos de ver están sin duda marcadas por la incidencia, a veces excesiva, que ha tenido la doctrina del margen de apreciación nacional en aquellas cuestiones que pueden cuestionar soluciones nacionales en ámbitos de especial sensibilidad para los Estados. Desde las conocidas Hadyside v. Dinamarca y Kokinakis c. Grecia ${ }^{25}$, tanto la moralidad pública

${ }^{23}$ Caso Otto Preminger Institute vs Austria, Sentencia del TEDH de 24 de septiembre 1994.

${ }^{24}$ Caso Wingrove vs Reino Unido, Sentencia del TEDH de 25 de noviembre de 1996.

${ }^{25}$ Caso Kokkinakis vs Grecia, Sentencia del TEDH de 25 de mayo del 2003 
como las propias relaciones del estado con lo religioso son cuestiones donde los estados miembros disfrutan de un amplio margen de apreciación a la hora determinar su marco normativo. Ahora bien, esta jurisprudencia evidencia también una circunstancia más relevante para el objeto de este trabajo y esa es la ausencia en la jurisdicción de Estrasburgo de un concepto libertad artística autónomo, que atienda a las peculiaridades que diferencian de esta forma de expresión de otro tipo de manifestaciones del espíritu. En realidad, como ya se dijo, lo que singulariza el tratamiento de la obra artística en esta jurisprudencia es precisamente el perfil bajo de su protección jurídica, en tanto no se le reconoce esa dimensión objetiva o institucional dentro de un estado democrático con la que normalmente se asocia a las libertades de expresión e información. Esta falta de reconocimiento es algo que creo puede constatarse si tomamos en consideración otros supuestos donde la protección de la moralidad o los sentimientos religiosos alegada por los Estados no sirvió para que el Tribunal admitiera como legítimas las injerencias en el artículo 10 del Convenio.

Este sería el caso, por ejemplo, de la sentencia Ginewski c. Francia ${ }^{26}$, en el cual, el Tribunal consideró que suponía una vulneración del artículo 10 del Convenio la sanción civil impuesta a un periodista que en un artículo de prensa había vinculado la doctrina de la Iglesia Católica con el antisemitismo y con el propio genocidio del pueblo judío. Y también de Aydin Tatlav c. Turquía $^{27}$, una sentencia en la cual la mayoría de los jueces concluyen que Turquía había vulnerado el Convenio al condenar penalmente al autor de un libro que juzgaba con severidad la religión islámica ${ }^{28}$. En ambos casos, y al contrario de lo que acabamos de ver en Otto Preminger y en Wingrove, la contribución específica de la libertad de expresión a la formación de la opinión pública dentro de una sociedad democrática, conduce al Tribunal a afirmar la posición preferente de esta libertad frente a las tentativas de excluir del debate público ciertas opiniones que pueden considerarse ofensivas para determinados grupos religiosos.

En cualquier caso, y paradójicamente, si algo pone de manifiesto que en la jurisprudencia de Estrasburgo la libertad artística no posee la plusvalía propia de la libertad de expresión política o de la libertad de información, son aquellos supuestos en los cuales el Tribunal sí ha condenado a los estados por las restricciones impuestas a la libertad artística. En uno de ellos, Bildender Künstler c. Austria ${ }^{29}$, el material artístico cuya exhibición había sido prohibi-

${ }^{26}$ Caso Ginewski vs Francia, Sentencia del TEDH de 13 de Enero 2010.

27 Caso Aydin Tatlav vs Turquía, Sentencia del TEDH de 2 de mayo 2006.

${ }_{28}$ Sobre esta jurisprudencia, véase, ampliamente, MARTínEZ TORRÓN, J., «La ofensa a la religión como límite a la libertad de expresión: la experiencia europea», en VV.AA., Medios de Comunicación y Pluralismo religioso, Consell de l'Audiovisual de Catalunya, marzo, 2010, pp. 79-100.

${ }^{29}$ Caso Bildender Künstler vs Autriche, Sentencia del TEDH de 25 de enero de 2007. 
da por las autoridades austriacas dado su carácter obsceno era una pintura satírica en la que aparecían retratados en clara actitud sexual varios líderes del Partido Liberal Austriaco (FPÖ), entre ellos su en aquel entonces presidente M. Haider, junto con la monja Teresa de Calcuta. A diferencia de un supuesto similar como el juzgado en Müller, en esta ocasión la mayoría del Tribunal atiende a las particularidades de la tradición artística satírica y también a la propia dimensión pública de los políticos que habían sido satirizados. Dos circunstancias que, unidas al hecho de que la prohibición decretada por las autoridades judiciales austríacas no tenía ninguna limitación de tiempo y lugar, conducen a la mayoría del Tribunal a declarar que este caso sí se había producido una vulneración del artículo 10 de Convenio. La segunda de estas sentencias es Karata c. Turquía ${ }^{30}$, en esta ocasión, la obra que había dado lugar al litigio era poética, en concreto, se trataba de un poemario, The song of a Rebelion, una composición de marcado tono épico en la que el autor glorificaba la resistencia kurda contra el gobierno de Turquía, invitando al pueblo turco a la resistencia y a la lucha. Las autoridades turcas condenaron al autor de estos versos por un delito de difusión de propaganda separatista, una condena que la mayoría de los miembros del Tribunal consideró que era contraria al artículo 10 del Convenio. El Tribunal toma en consideración en su sentencia, el impacto reducido que puede tener la obra en cuestión en la sociedad, al tratarse de una composición poética, destinada a un público en principio minoritario, pero también, la propia dimensión política de la obra, valorando, en este sentido, la contribución específica que esta obra, o este tipo de obras, pueden hacer una sociedad democrática. En definitiva, tanto en Karata como en Bildender Künstler, es la explícita dimensión política del discurso, pero no el soporte artístico de la expresión, lo que parece determinar la plusvalía de la libertad artística en el juicio de ponderación realizado por la Corte ${ }^{31}$. Podríamos decir que, al contrario del pensamiento vanguardista, el mensaje político explícito ennoblece para el Tribunal la obra de arte, por lo menos a los efectos de equiparar su tratamiento jurídico al de otras manifestaciones de la libertad de expresión, tradicionalmente objeto de una protección específica. A la manera de León Felipe, el Tribunal parece, no sé si maldecir, pero sí por lo menos, discriminar, la poesía de los que, de una u otra forma, no toman partido político expreso.

Desde mi punto de vista, este tratamiento de la libertad artística, como una libertad débil, siempre y cuando no pueda encuadrarse en el concepto de arte político, parte de un cierto desconocimiento o infravaloración de los réditos sociales que reporta una cultura artística en libertad. En primer lugar,

${ }^{30}$ Caso Karata vs Turquía, Sentencia del TEDH de 8 de Julio de 1999.

${ }^{31}$ Coincidimos, en este sentido, con PAUl KeARns, quien realiza un detallado examen de esta jurisprudencia en «The Judicial Nemesis: Artistic Freedom and the European Court of Human Rights», Irish Law Journal, 2012, pp. 75-92. 
jerarquizar el impacto social o político de las manifestaciones del espíritu puede ser en muchas ocasiones una operación apócrifa, y es que es difícil de valorar la incidencia -también en términos políticos- que puede tener una determinada obra en una sociedad a lo largo del tiempo. Obviamente, Madame Bovary o De Profundis no son trabajos literarios que se puedan circunscribir en el concepto de arte político, pero creo que nadie negaría que han tenido una incidencia real en la configuración de ciertos horizontes de emancipación en las relaciones humanas en una sociedad determinada ${ }^{32}$. No es extraño tampoco que el arte horade, de forma consciente o no, el terreno de lo simbólico desde un punto de vista político. Pese a que una obra artística nazca desde la más pura asepsia ideológica, en cierta medida su significado deja de ser propiedad del autor desde el momento en que la sociedad se apodera de ella, pudiéndola convertir en símbolo de algo completamente ajeno a la voluntad originaria de su creador. Desde luego ni la Novena Sinfonía de Beethoven ni la Oda a la alegría de Schiller nacieron para ser símbolos de la unión política de Europa. Los artistas, en definitiva, pueden coadyuvar en la legitimación o en la deslegitimación de las repúblicas, incluso sin querer. Del mismo modo, como señalamos en el artículo anterior, hay expresiones artísticas que precisamente por su carácter marcadamente apolítico, pueden ser observadas con especial atención desde el terreno propiamente político, sin que la ausencia de figuración o de inteligibilidad en el relato prive a la obra artística de esa posibilidad de transmitir a algunos una idea política e incluso una idea política compleja ${ }^{33}$.

En definitiva, la expresión artística penetra y afecta a la comunidad política. Puede fortalecer o cohesionar una determinada comunidad, del mismo modo que puede generar subculturas que pongan en cuestión o exterioricen las debilidades de la cultura política hegemónica. No obstante, también en ese sentido, o incluso, especialmente en este sentido, la libertad artística adquiere una importancia objetiva excepcional dentro del Estado Constitucional, en tanto, constituye una expresión visible de ciertas patologías sociales que en muchas ocasiones va a manifestarse en espacio de reflexión específico que es el arte que en la propia comunidad. Por ello, al igual que no puede existir un estado constitucional sin medios de comunicación libres, tampoco es imaginable sin artistas que realmente lo sean. Creo que lo que intento defender hasta ahora, un concepto fuerte de libertad artística dentro de la Constitución, equiparable a otras manifestaciones de la libertad de comunicación

${ }^{32}$ Sobre la incidencia de la pintura en el aprendizaje de la sexualidad, puede verse Argullol, R., Una educación sensorial. Historia personal del desnudo femenino en la pintura, Barcelona, 2012.

${ }^{33}$ Como señala Peter Weiss en su Estética de la Resistencia, y en relación al Gernika de Picasso: «sin que ninguno lo comprendiéramos, vimos lo que ocurría en España». WeIss, P., La estética de la resistencia, Ed Hiru, Hondabarria, 1999, p. 378. 
con las libertades de expresión e información, se puede condensar muy bien en la forma en la que un autor como Habërle ubica la libertad de creación artística entre los presupuestos del Estado Constitucional. La cita literal creo que vale la pena:

«Las garantías de defensa y de protección jurídica de la libertad artística y de la literaria junto con sus respectivos autores en particular despliegan todo su sentido político-constitucional específico en la medida en que con ello el propio estado constitucional se auto-protege, es decir en la medida en que intenta garantizar la protección de sus propias premisas, ya que tanto la literatura como sus respectivos literatos son requisitos vitales de dicho Estado» ${ }^{34}$.

\section{EL ARTISTA Y EL DERECHO A LA IRREVERENCIA}

Empezábamos este trabajo llamando la atención sobre la requerida modestia con la que el derecho constitucional ha de moverse en territorios conceptuales que no le son propios. Definir qué es arte, del mismo modo que definir qué es religión es demasiada tarea para un mero jurista ${ }^{35}$, y un buen consejo a seguir es el que diera el juez Holmes en Bleistein v. Donalsen ${ }^{36}$, de evitar en lo posible definir en abstracto qué puede ser calificado de obra de arte. Para Holmes

«It would be a dangerous undertaking for persons trained only to the law to constitute themselves final judges of the worth of pictorial illustrations, outside of the narrowest and most obvious limits. At the one extreme, some works of genius would be sure to miss appreciation. Their very novelty would make them repulsive until the public had learned the new language in which their author spoke. It may be more than doubted, for instance, whether the etchings of Goya or the paintings of Manet would have been sure of protection when seen for the first time...».

Efectivamente, como señala Holmes, no han sido pocos los casos en los que lo que en un momento no fue considerado arte o incluso produjo la risa -como cuenta Bataille de la Olympia de Manet- luego pasa a la historia como una obra maestra, en definitiva como un canon de excelencia ${ }^{37}$. En cualquier caso, igual que sin necesidad de definir qué es religión podemos

${ }^{34}$ Haberle, P., Teoría de la Constitución como ciencia de la Cultura, Ed. Tecnos, Madrid, 2000, p. 56

35 Sobre estas dificultades, véase, en extenso, Haight Farley, C., Tulane Law Review, Vol. 79, 2005, en especial, pp. 810-819.

${ }^{36}$ Asunto Bleistein v. Donaldson Lithographing Company, Sentencia del TS de EEUU de 1903 (188 U.S. 239).

37 Vid. Bataille, G., Manet, Ed. Tecnic, Valencia, 2003, p. 34. 
afirmar que hay iglesias y reconocerlas, también podemos, sin necesidad de adentrarnos en una definición jurídica de arte, afirmar que hay artistas y saber quiénes son. Incluso puede resultar cómodo aceptar como punto de partida, aquello que propone el historiador del arte Gombrich, que no existe propiamente el arte, que tan solo hay artistas ${ }^{38}$. Desde luego, esta postura sería acorde con los presupuestos de una sociedad abierta de intérpretes constitucionales, en donde habría que asumir que la interpretación de qué es la libertad artística es sobre todo competencia principal de los literatos, pintores, músicos... En definitiva, más que definir en abstracto el derecho que actos encajan o no en la definición, parece más modesto atender a la definición, al «plebiscito informal» que sobre este derecho llevan a cabo sus intérpretes, o si se prefiere, sus hacedores, naturales.

En este sentido, si tomamos en consideración a los artistas y «aquello que los artistas hacen», creo que hay varios aspectos que pueden tener relevancia de cara a dar un tratamiento jurídico autónomo a esta libertad. El primer aspecto está relacionado con la propia vinculación de la creación artística con la identidad del autor. Hasta ahora hemos podido ver cómo la libertad artística no era ajena a los dos valores que subyacen en la protección de la libertad de expresión: su contribución la cultura política y a la existencia de un «libre mercado de ideas». Pues bien, la libertad artística está vinculada, y creo que de una manera especialmente intensa o única, a otro valor tradicionalmente adscrito a la libertad de expresión, como es el de la autonomía personal o el libre desarrollo de la personalidad. En buena medida, por suerte o por desagracia, desde el Romanticismo en adelante, la creación artística ha abandonado toda pretensión de verdad, y ha estado marcada por un subjetivismo radical. La hipertrofia del yo ha establecido en cierta medida el criterio de distinción entre el artesano y el artista ${ }^{39}$. A este subjetivismo, se ha unido lo que podríamos llamar una suerte de fe en la obra. Despojada de su labor cultual u ornamental, la creación artística, en el escenario del arte por el arte, y al margen de cualquier pretensión de utilidad práctica, adquiere en sí misma una suerte de trascendencia. En este sentido, como apunta Gadamer, hay algo de teología en el arte moderno igual que hay una cierta aura de mesianismo en la figura del artista ${ }^{40}$. Desde luego, lo que parece claro es que en la obra de arte el artista vuelca su yo de una forma única, hasta el punto que si tomáramos en consideración la distinción de Ortega entre ideas y creencias podríamos decir que el artista cree en la obra, está de alguna forma en ella.

${ }^{38}$ GomBrich, E., Historia del Arte, 1982, p. 113.

39 Véase, las páginas que a ello dedica en un trabajo que considero imprescindible, OVEJERO DE LuCAS, F., El compromiso del creador. Ética de la estética, Ed. Galaxia Gutenberg, Barcelona, 2014, en especial, pp. 62 y ss.

40 Vid. Gadamer, H.-G., La actualidad de lo bello, op. cit., p. 59-60. Sobre ello incide especialmente ARGUlLOL, R., en su estudio introductorio a esta misma obra, pp. 10-212 
Junto este subjetivismo radical, otro elemento que ha caracterizado gran parte del quehacer artístico ha sido la irreverencia, la desatención, en ocasiones ostentosa, hacia la moral establecida. «Mi superioridad reside en que no tengo corazón», diría Rimbaud, elevando esta irreverencia a su máxima expresión. Desde estos presupuestos, el artista se ha erigido en una suerte de violador natural del tabú en el seno de la sociedad, lo cual le ha situado, obviamente, en la frontera de la legalidad. El artista ha sido, en este sentido, uno de los principales blancos de ese derecho de la moralidad que defendiera Lord Devlin en su polémica con Hart ${ }^{41}$. Un derecho que se pone al servicio de la integridad moral de la sociedad, sancionando aquellos discursos que provocan un profundo y verdadero sentimiento de repugnancia y que por ello amenazan con desestructurar moralmente la comunidad. Las normas que protegen a la sociedad frente a lo obsceno o lo sacrílego han constituido los límites casi congénitos de un espacio, el artístico, que se ha comprendido a sí mismo sin rendir tributo a otros valores que no sean estéticos, o que no estén relacionados con la propia libertad del creador. Los protagonistas de este conflicto no han sido ni mucho menos de talla menor; si préstamos atención solo al ámbito de la literatura, la censura de la moralidad ha afectado a la obra de autores como Balzac, Flaubert, Joyce, Navokov o D. H. Lawrence, por citar sólo a algunos de los más reputados, sin olvidar que han sido también muchos los autores menores o mediocres, que confundiendo la excelencia con la transgresión han terminado al margen de este derecho de la moralidad. Obviamente, los primeros de alguna forma nos sirven como una señal histórica de alerta, y es que, aquello que un día fue considerado inmoral, con paso del tiempo, no mucho, puede convertirse en canon ya no sólo estético, sino en cierta medida también cultural de una determinada sociedad. Los artistas, y especialmente la literatura, pero no exclusivamente ella, han realizado en este sentido una suerte de labor de prospección moral que no se limita a la mera reflexión estética.

En cualquier caso, tampoco podemos descartar que los segundos, aquellos que confunden excelencia con provocación o trasgresión, puedan iluminarnos a la hora de comprender la dinámica jurídica de la liberta artística. Como diría un autor norteamericano, uno nunca sabe dónde se encuentran los héroes de la Primera Enmienda. En este sentido, la casuística de la libertad artística nos pone de manifiesto que esta forma de expresión no va a tener como límite, en la mayoría de los supuestos, normas que protegen frente a un peligro de daño real y cierto. Algo que, si se piensa, es en cierta medida lógi-

${ }^{41}$ Devlin, L., The Enforcement of Morals, Oxford, 1959.; HART, H.L.A., Law, Liberty and Morality, Oxford, 1963. Igualmente, una crítica clásica a la obra de Devlin, también desde presupuestos liberales, la podemos encontrar en DWORKIN, R., «Lord Devlin and the Enforcement of Morals», Yale Law Journal, Vol. 75, 1987, 1965-1966. 
co, pues normalmente el arte como medio imaginativo no juega con lo real ${ }^{42}$. Es decir, nadie entiende que el escritor de novela negra que recrea con todo lujo de detalles una serie de asesinatos que han quedado impunes está incitando al asesinato o cantando a la impunidad, sino que lo normal es pensar que esa historia está escrita así porque de esa forma ha encontrado su autor un vehículo para provocar una determinada emoción en el lector. Es por ello que, si bien su influencia sobre la cultura o la opinión pública pueda ser muy intensa, resultan insólitos los supuestos en los que el arte pueda provocar un daño real y cierto en bienes jurídicos concretos. Es difícil, podríamos decir, encontrar supuestos en los cuales la expresión artística, que se mueve, por definición, en el territorio de lo figurativo y lo imaginado, pueda ser comprendida dentro del concepto de fighting words. Las balas del artista en este campo pueden ser consideradas balas de fogueo. Por ello son dos conceptos jurídicos tan indeterminados como la protección de la moralidad o de los sentimientos religiosos, y no derechos o bienes jurídicos concretos, los que han constituido los límites naturales a la libertad de expresión artística. Límites que creo que envejecen mal en el contexto de una sociedad pluralista.

En primer lugar, como afirma un autor como Waldron, quien no duda en defender la tipificación penal del discurso del odio, una cosa es defender a través del derecho lo que las personas son y otra lo que las personas piensan o creen ${ }^{43}$. Sin duda, en una sociedad pluralista, donde conviven distintas visiones de lo bueno y lo justo, lo segundo constituye un límite jurídico cuya fundamentación es mucho más débil. En este sentido, en relación con la protección de los sentimientos religiosos creo que es difícil no estar de acuerdo con la tesis que en su día avanzara el juez Frankfurter en la conocida sentencia Joseph Burstyn, Inc. v. Wilson ${ }^{44}$, en donde se trataba de valorar la adecuación a la Primera Enmienda de la prohibición que había decretado el Estado de New York contra la exhibición y distribución de la película del director italiano Roberto Rossellini El milagro. Para ello, el Estado de New York se había apoyado en una normativa educativa que vetaba la exhibición de contenido sacrílego. En concreto, lo sacrílego de la película «El milagro» era el relato que ésta hacía de cómo San José dejaba embarazada a una campesina demente, haciéndola luego creer que era la Virgen María. Pues bien, para la Corte Suprema, la Primera Enmienda de la Constitución no permite a los poderes públicos establecer restricciones previas a la libertad de expresión con el objetivo de proteger la religión o determinadas comprensiones religiosas de aquellas visiones de las mismas que puedan resultar incómodas.

42 Sobre este tributo al compromiso artístico con la mentira, puede leerse a WILDE, O., La decadencia de la mentira, Madrid, 2000.

43 Waldron, J., Harm in Hate Speech, Harvard-Cambridge, 2012, pp. 118-131.

${ }_{44}$ Asunto Joseph Burstyn, Inc. v. Wilson, Sentencia del TS de EEUU de 1952 (343 U.S. 495). 
La sentencia del Tribunal en Joseph Burstyn, Inc. v. Wilson avanzaba así una nueva comprensión, luego consolidada, de la obra cinematográfica como manifestación de la libertad de expresión ${ }^{45}$, al tiempo que rechazaba que el Estado pudiera esgrimir como interés legítimo para su limitación la salvaguarda del dogma religioso ${ }^{46}$. Pero, como decía, creo que las páginas más esclarecedoras de este litigio, en relación con la cuestión que nos ocupa, se encuentran en el voto particular concurrente del Juez Frankfurter, quien acude a la propia idea de pluralismo para fundamentar la imposibilidad constitucional de proteger lo sagrado en un contexto como el estadounidense. Para el juez, el estado de New York había dado sentido jurídico al concepto de «sacrilegio» a través, exclusivamente, de los textos de Agustín de Hipona y del padre Tomás de Aquino. Sin embargo, después de bucear por distintos diccionarios de la lengua inglesa para intentar dotar de un significado secular a este concepto, Frankfurter demuestra la imposibilidad de encontrar una idea común de lo "sacrílego»" ${ }^{47}$ en un lugar donde el pluralismo religioso es tan exacerbado que, parafraseando al juez Roberts en Cantwell v. Conneticut, resulta habitual que las creencias y las propias conductas religiosas de uno puedan resultar sacrílegas para su vecino ${ }^{48}$. En definitiva, si aceptamos que la moral y la religión son cuestiones que en un estado constitucional de cuño pluralista han de reconducirse al ámbito de lo privado, conceptos como el de obscero o el de sacrílego no pueden ser comprendidos sino de forma débil a la hora de imponerse a un derecho como la libertad artística.

Tomando en consideración lo anterior, creo que es importante insistir en que categorías jurídicas como la de lo obsceno no pueden en ningún caso, no ya limitar, sino delimitar el derecho a la libertad de creación artística, de tal forma, que las manifestaciones susceptibles de ser consideradas como tales, es decir obscenas, queden fuera del ámbito amparado por el derecho. En realidad, pienso que el razonamiento ha de ir en un sentido contrario. Aquello a lo

${ }^{45}$ Con esta sentencia, la Corte Suprema deroga el precedente establecido en el Asunto Mutual Film Corp. v. Industrial Commission, Sentencia del TS de EEUU de 1915 (236 U.S. 230), una decisión en la cual la mayoría del Tribunal había interpretado que el cine era propiamente un producto industrial que, en ningún caso, podía verse amparado por la Primera Enmienda como una aquellas manifestaciones de la libertad de expresión que, de alguna forma, contribuyen a la formación de opinión pública.

46 Sobre las muchas implicaciones, también económicas, de este cambio jurisprudencial, puede verse, en extenso, Wertheimer, J., «Mutual Film Reviewed: The Movies, Censorship, and Free Speech in Progressive America», 37 The American Journal of Legal History, April 1993, pp. 158-189.

47 (Frankfurter Concurring) Joseph Burstyn, Inc. v. Wilson 343 U.S. 507-540, (1952) «...in America, the multiplicity of the ideas of «sacredness» held with equal but conflicting fervor by the great number of religious groups makes the term «sacrilegious» too indefinite to satisfy constitutional demands based on reason and fairness».

48 Vid. Cantwell v. Connecticut, 310 U.S. 296 (1940). 
que pueda reconocérsele un valor artístico no puede ser censurado por su obscenidad, su lascivia o su indecencia. Este ha sido, en gran medida, el razonamiento judicial que se ha impuesto en la jurisprudencia de la Corte de Suprema de los Estados Unidos, a través del obscenity test que establece en la conocida sentencia Miller v. California ${ }^{49}$, y en virtud del cual, se excluye que puedan ser censuradas por obscenas, aquellas manifestaciones de la libertad de expresión que siendo subsumibles dentro del concepto de obscenidad, al ser valoradas en su conjunto muestren un serio valor artístico o literario ${ }^{50}$.

En definitiva, y por concluir, el derecho a la libertad artística necesariamente engloba lo que Vargas Llosa ha definido como el derecho a la irreverencia ${ }^{51}$. Sin esta posibilidad de atacar la moralidad, la libertad de artística no sólo deja de ser reconocible como tal, sino que en buena medida pierde esa capacidad prospectiva y emancipadora que le es propia dentro de una sociedad y que justifica, como se ha defendido en este trabajo, una protección jurídica equiparable a la de las libertades de expresión e información. En cierta medida, esta especial relación del arte con lo prohibido no deja de ser paradójica, ya que si bien la creación artística reclama un ámbito de máxima libertad, en muchas ocasiones podríamos decir, parafraseando a Eugenio D’Ors, que sus límites han sido su riqueza, y ello, en tanto, el culto a la transgresión necesita obviamente, normas que transgredir. En cualquier caso, el rifirrafe del creador con la moralidad o con el derecho de la moralidad en un determinado lugar y tiempo, siempre encuentra escenarios inéditos y casos difíciles que agitan a una sociedad y le hacen replantearse o refirmarse en sus ideas. Valga como ejemplo para terminar esta primera aproximación a la libertad artística, la reciente sentencia de la Corte Constitucional de Colombia anulando la prohibición de las corridas de toros en Bogotá, sobre la base de que ésta vulnera la libertad artística y afecta a una de las manifestaciones del pluralismo cultural del país $\mathrm{s}^{52}$. Un caso difícil, sin duda, pero que también confirma aquel aforismo de José Bergamín, por extensión aplicable a todas las manifestaciones artísticas, de que los toros son un espectáculo inmoral y por ello educador de la inteligencia.

\section{TITTLE: The Artistic Freedom. A First Approach.}

RESUMEN: En el presente trabajo se va a defender una comprensión fuerte de la libertad artística como derecho constitucional. Para ello, se intentarán refutar algunas de las objeciones doctrinales y judiciales que se oponen a la extensión a este derecho del tratamiento jurídico de las liber-

49 Asunto Miller v. California, Sentencia del TS de EEUU de 1973 (413 U.S. 15).

50 Asunto Miller v. California, Sentencia del TS de EEUU de 1973 (413 U.S. 15, 24-25).

51 Vargas Llosa, M., «El derecho a la irreverencia», El País, 22 de febrero de 2006.

52 Asunto T-296/13, Sentencia de la Corte Constitucional de Bogotá D.C. de 22 de mayo de 2013. 
tades de expresión y de información. En concreto, aquella que niega una igual importancia institucional de este derecho dentro del Estado Constitucional. Finalmente, se tomarán en consideración algunas especificidades de las manifestaciones de este derecho, como su irreverencia y su radical individualismo, para justificar un concepto autónomo de libertad artística, resistente a los límites del denominado derecho de la moralidad.

PALABRAS CLAVE: libertad artística, libertad de expresión, libertad de información, derecho constitucional, irreverencia.

ABSTRACT: In this paper we'll try to defense a strong constitutional concept of artistic freedom. First, we try to refute some of the doctrinal and judicial objections against the extension of the legal treatment of freedoms of speech and press to the artistic freedom. Specifically, the one denies the equal institutional and democratic relevance to the artistic works within the constitutional state. Finally, we will defense an autonomous concept of artistic freedom, especially against the limits based on obscenity law.

KEYWORDS: artistic freedom, freedom of expression, freedom of information, constitutional right, irreverence. 